\title{
Formação de professores em instituições públicas de ensino superior no Brasil: diversidade de problemas, impasses, dilemas e pontos de tensão
}

\section{Teacher training at public high education institutions in Brazil: a diversity of problems, impasses, dilemmas, and tension points}

\author{
Clara Brener Mindal ${ }^{1}$ \\ Ettiène Cordeiro Guérios ${ }^{1}$
}

\begin{abstract}
RESUMO
Este artigo apresenta problemas, impasses, dilemas e pontos de tensão atuais na formação de professores para a Educação Básica em instituições públicas brasileiras. Os dados da pesquisa documental exploratória advêm de levantamento de teses registradas no Banco de Teses da Coordenação de Aperfeiçoamento de Pessoal de Nível Superior (Capes) e artigos publicados no site da Scientific Eletronic Library Online (SciELO)/Brasil. Foi realizado levantamento de trabalhos publicados no período de 2006 a 2013. Encontramos problemas, impasses, dilemas e pontos de tensão relacionados à profissão docente, aos cursos de formação de professores e referências a pouca atratividade docente e falta de professores.
\end{abstract}

Palavras chave: formação de professores; licenciaturas; ensino fundamental.

\begin{abstract}
The matter of this article is a diversity of problems, impasses, dilemmas, and tension points present at teachers training for basic education in Brazilian public high education institutions. Data for the exploratory documental investigation comes from the registered theses at the Coordenação de
\end{abstract}

1 Universidade Federal do Paraná. Setor de Educação. Curitiba, Paraná, Brasil. R. General Carneiro, $\mathrm{n}^{\circ}$ 460. CEP: 80060-150. 
Aperfeiçoamento de Pessoal de Nivel Superior (Capes) Theses Bank and articles published on the Scientific Eletronic Library Online (SciELO)/Brazil website. The investigation period ranges from 2006 to 2013. We found problems, impasses, dilemmas, and tension points related to the teaching profession, teachers education courses, and career attraction.

Keywords: teachers training; teachers education; licentiate degree; basic education.

\section{Introdução}

A formação de professores para o ensino básico é discutida no Brasil há muito tempo. As questões debatidas são recorrentes e ampliadas e, a cada época, mais elementos, vetores, indicadores, análises e temáticas são inseridos nas discussões. Atualmente, diversos trabalhos têm ampliado a discussão, mostrado a complexidade do tema e a perplexidade que surpreende àqueles que por ele se interessam: discute-se muito, mas na prática parece pouco o reflexo no avanço qualitativo da formação.

Organizamos a apresentação do tema deste texto, iniciando pelo resgate de ideias de dois artigos: um de 1992 e outro de 2000, portanto trabalhos publicados há 21 e 13 anos respectivamente. A escolha, proposital, mostra historicamente a recorrência das questões que tratamos, mais ainda se consideramos que aquele de 1992 recorre em parte a uma pesquisa que abarca o período de 1950 a 1985.

Com efeito, em 1992, no artigo A formação docente: o confronto necessário Professor x Academia, Gatti retrata a formação de professores para o ensino básico que, à ocasião, ocorria em sua maior parte em instituições isoladas de ensino superior e não em universidades. Funcionamento precário e qualificação discutível. Menciona a inércia das universidades para tratar o tema das licenciaturas durante aquele período, somado à dificuldade de autocrítica e de mudança.

No artigo, a autora discute questões relacionadas à formação de professores para o ensino básico fazendo referência ao estado da arte sobre a formação de professores realizado por Silva e publicado em $1991^{2}$, que caracterizava a formação de professores no período que vai de 1950 a 1986. O magistério era a área que mais congregava estudos analíticos e já era difícil avaliar a contribuição desses estudos para o aperfeiçoamento da formação.

2 Silva, Esposito, Sampio e Quinteiro (1991). 
O perfil do profissional docente merecia análise e discussão, no entanto, o perfil desejável sofria de imprecisão.

A análise dos currículos dos cursos de formação de professores nas universidades mostrava que eram alvos de críticas: podiam ser elitistas, idealistas, enciclopédicos ou, ao contrário, aligeirados, superficiais tanto na formação específica quanto na geral; mas, o que talvez fosse pior é que as próprias análises também eram superficiais.

Gatti (1992) comenta que enfoques teóricos diferentes embasavam a formação de professores ora com base na psicologia, ora com base na sociologia, ambos em detrimento do enfoque pedagógico, situação que se repete no início da década de noventa. Na atualidade, percebemos que esses enfoques concorrem nos estudos sobre a formação de professores com perspectivas filosóficas e epistemológicas diversas. Nada mal, se os enfoques não concorressem entre si pela hegemonia na análise e na prescrição pedagógica em vez de enriquecer interdisciplinarmente a complexidade educativa.

Outro ponto ressaltado por Gatti (1992) se referia ao tratamento do professor como um ente genérico e abstrato. A esse respeito, a autora observa que, de modo similar, pouco se considerava o dia a dia concreto do professor, as situações que enfrentava em seu trabalho, as necessidades que se colocavam e as implicações para a sua própria vida, seu pensamento e sua atuação. Isto é, pouco se considerava a experiência e o conhecimento acumulado pelo sujeito professor.

Pontos de tensão recorrentes na formação de professores nas universidades mencionados por Gatti derivavam das relações entre as áreas específicas de conhecimento e dos componentes gerais das áreas das ciências da educação, entre os quais, até aquele momento, existia pouca articulação. As relações entre essas áreas passam por questões econômicas e organizacionais, pela estrutura departamental de muitas universidades, pelas diferenças entre a formação na habilitação do bacharel e do licenciado, pelas diferenças de finalidade formativa e metodológica, entre outros pontos críticos de tensão a serem debatidos, pensados em diferentes estruturas e relações.

Em suma, os pontos mencionados por Gatti que mereciam reflexão, ainda não resolvidos ou mal equacionados, estavam relacionados às instituições formadoras, aos estudos sobre formação, ao perfil do profissional a ser formado, aos currículos, às disciplinas. Também foram mencionadas as necessidades formativas em face: das necessidades concretas dos professores e das situações sociais existentes, da formação dos formadores, dos materiais didáticos utilizados na formação, da incorporação de novas tecnologias e dos enfoques teóricos que dão base à formação como prática ou como objeto de estudo. 
Como é possível perceber, Gatti analisou no início da década de 1990 problemas e tensões relacionados à formação de professores presentes e em pauta praticamente desde a década de 1950.

Dez anos depois, frente situações similares e recorrentes na formação de professores, Pereira (2000) atribui muitas das dificuldades de implementação de mudanças significativas nos cursos de formação de professores no ensino superior público e os diversos problemas da formação nesse âmbito ao descaso com que as universidades tratavam a questão da formação de professores em função das relações de poder dentro das universidades, dentre as quais menciona as: de força, de lutas e de estratégias, de diversos interesses e de questões econômicas lucrativas, que se estabeleceram ao longo da história das instituições de formação superior no Brasil. Tal situação acabou por valorizar de maneira desigual a pesquisa e o ensino, a pós-graduação comparada à graduação, o bacharelado em relação à licenciatura. Essa situação coloca desafios de solução complexa que, na formação de professores, se somaram à desvalorização geral que no Brasil sofre o profissional da área educacional, especialmente suas condições de vida e de trabalho que continuam sem solução no ano de 2000 , quando se publica o artigo.

\section{Problemas, impasses, dilemas e pontos de tensão atuais na formação de professores em instituições públicas brasileiras: período de 2006 a 2013}

Neste artigo temos por objetivo mostrar um levantamento de diversas questões colocadas sobre a formação de professores nas universidades públicas brasileiras nos últimos anos - 2006 a 2013 - evidenciando a diversidade de problemas, impasses, dilemas e pontos de tensão que aparecem como conflitantes nos debates sobre formação de professores.

Realizamos pesquisa documental exploratória nos resumos de teses do Banco de Teses da Capes e em artigos publicados online no site SciELO/Brasil. Delimitamos o período de 2006 a 2012/13 e utilizamos os descritores: "formação de professores" e "licenciaturas" para a busca inicial. Uma primeira seleção se deu pela leitura dos títulos e a segunda, pela leitura dos resumos. Foram lidos na íntegra os trabalhos selecionados no site SciELO após a leitura dos resumos. Das teses, utilizamos os resumos.

Em grande maioria, os resumos de teses selecionados referem-se a questões sobre a formação de professores, estudadas a partir da análise de cursos 
específicos: entre eles os mais frequentes são os cursos de química, educação física, matemática, pedagogia e física.

Mindal (2006), por exemplo, mapeou em sua tese os principais aspectos abordados nos estudos sobre graduação com base nos textos apresentados nas reuniões da Associação Nacional de Pós-Graduação e Pesquisa em Educação (ANPEd), no período entre 1996 e 2003 e encontrou maior incidência de estudos sobre os cursos de Pedagogia e Matemática.

Da leitura dos textos selecionados para este artigo, emergiram três grandes temas debatidos de modo geral pela maioria dos autores. O primeiro trata de questões relacionadas à formação para exercer a profissão de professor de ensino básico, iniciada e parcialmente efetivada nos cursos de licenciatura ou nos cursos de pedagogia das universidades públicas. O segundo trata dos cursos de formação de professores, problemas, tensões e dificuldades a eles relacionados no âmbito das instituições de ensino superior públicas. Por último, no terceiro grande tema, reunimos o que os autores falam sobre o que denominamos falta de atratividade da carreira docente. Como será possível perceber adiante, diversidade de problemas, impasses, dilemas e pontos de tensão apresentam recorrência em relação àqueles pontos mencionados por Gatti (1992) e Pereira (2000).

\section{Profissão}

Diversos autores enfatizam que o magistério é profissão complexa e muito difícil. Ressaltam que parte dessa complexidade advém da atividade dos professores por pertencerem ao grupo de profissões que lidam com formação e desenvolvimento de pessoas; das exigências feitas em termos educacionais e sociais; das atribuições específicas da profissão; e da diversidade de campos e níveis de ensino. Grande parte da complexidade da formação para professor e da própria atuação deriva das dimensões objetivas e subjetivas do ser professor.

Um dilema está em como considerar, na formação inicial, a dimensão objetiva e a subjetiva da prática pedagógica na escola. O imprevisível e o imponderável são partes constituintes da ação pedagógica, tanto na perspectiva didática quanto na perspectiva emocional da ação docente (GUÉRIOS, 2002). Se, por um lado há o engajamento em função da relação professor-aluno, por outro lado, muito do exercício profissional se dá entre quatro paredes, o que demanda decisões individuais, imediatas e, não raramente, isoladas. A este respeito, é possível concordar com Lüdke e Boing (2012, p. 448) quando dizem 
que "Há uma dose considerável de aspectos imprevisíveis em toda sala de aula e um componente importante de criatividade e iniciativas na alçada do professor."

Alguns autores mencionam a identidade profissional, os conhecimentos e habilidades necessários ao exercício profissional. É o que podemos notar em Frison (2012), cuja tese teve os objetivos de investigar e analisar os saberes docentes e as aprendizagens sobre conhecimentos profissionais de professores construídos durante a elaboração e o desenvolvimento de propostas de ensino, denominados Situações de Estudo (SEs). Buscou compreender que mudanças ocorrem nas ações de professores durante o desenvolvimento de propostas de trabalho que lhes permitem refletir sobre a própria prática. Observou que as propostas de ensino denominadas SEs, produzidas na formação inicial e desenvolvidas no espaço/tempo do estágio de docência, quando acompanhadas por pesquisa, aumentam seu potencial formativo, oferecem maiores chances para a (re)significação e a produção de conhecimentos profissionais de professor, favorecem a constituição de um professor reflexivo, mais autônomo e capaz de tomar decisões conscientes e contribuem para qualificar a formação, a atuação e o desenvolvimento dos estudantes.

\section{Cursos}

Quanto ao Curso de Pedagogia, é assinalada a grande complexidade curricular dos cursos de formação inicial, tendo em vista o amplo leque de atribuições definidas para o profissional egresso desse curso. Em função do tempo e da carga horária, Gatti (2010) enfatiza como problemática a existência de dispersão disciplinar que compromete a formação, bem como provoca tensões e impasses para o desenvolvimento desses cursos.

Discute-se recorrentemente a diferença da qualidade da formação do professor de áreas específicas em comparação com a formação do professor generalista para os anos iniciais no sentido de ressaltar que os conteúdos específicos que são ensinados nos anos iniciais não são objeto dos cursos de formação em pedagogia.

No que se refere aos cursos de Licenciatura, salientamos temas comuns encontrados nos documentos pesquisados que revelam conflitos, dilemas e pontos de tensão na formação de professores. Quanto aos Currículos (GATTI, 2010; LÜDKE; BOING, 2012; ROSSO, 2010; SAVIANI, 2009), é recorrente considerar que os modelos permanecem prescritivos, compostos por conhecimento fragmentado em múltiplas disciplinas e clara dicotomia entre o conhecimento 
teórico e o conhecimento prático, além do conhecimento específico de o que ensinar e como ensiná-lo.

Também, é recorrente mencionar a falta de propostas curriculares que façam interação entre a escola, os conhecimentos específicos e pedagógicos, a docência e a sociedade.

Vemos na tese de Marques (2010) que o perfil dos cursos de Licenciatura em Química das Instituições Públicas de Ensino Superior (IPES) da região Nordeste do Brasil apresenta segmentação entre as áreas de formação de conhecimento químico e pedagógico, e prevalece nesses modelos de curso e currículo, ainda, o modelo de formação de professor baseado na racionalidade técnica. O Estágio Supervisionado e a Prática como componentes curriculares nesses cursos foram as dimensões que apresentaram maiores incoerências durante o processo de implementação das mudanças sugeridas pela legislação.

Alguns autores discutem questões relacionadas às reformulações curriculares posteriores à publicação das Diretrizes Curriculares para as Licenciaturas, como pode ser visto a seguir.

A adequação dos cursos de formação de professores às Diretrizes Curriculares apresenta pontos de tensão sinalizados por Canan (2009). Em tese defendida em 2009, Canan pesquisou quais as tensões e os limites expressos nas Diretrizes Nacionais para a Formação de Professores da Educação Básica. Sinalizou que, naquele documento, o elemento nuclear da formação de professores é as competências para a empregabilidade, o que, no plano educativo, implica a adoção e vivência de uma postura compatível com o ideário do mercado de trabalho. O problema está em esse perfil reafirmar e manter a dicotomia entre formação específica e formação pedagógica a partir do momento em que impõe a prática como elemento central e base da formação docente. O processo de adequação dos cursos às Diretrizes analisado por Canan (2009) promoveu nas universidades pesquisadas a reavaliação dos projetos das licenciaturas. Processo cujo resultado foi a construção de novas propostas de formação e que exigiu do corpo docente maior aprofundamento para superar a tradicional dicotomia entre licenciatura e bacharelado e entre a área específica em que o professor irá atuar e a área pedagógica.

Como aponta Rosso (2010), reformulações realizadas em alguns cursos de licenciatura tomando por base as Novas Diretrizes Curriculares para as Licenciaturas mantiveram os estereótipos comuns às licenciaturas, os problemas e os conflitos presentes nos currículos anteriores. Outra investigação que teve por objetivo identificar o efeito das mudanças propostas nas Diretrizes Curriculares, realizada por Proença (2010), mostrou que não foi possível dar às licenciaturas a identidade de um curso de formação para a docência - tais cursos ainda apresentam as mesmas características desde a sua criação. 
A tensão entre matrizes curriculares diferentes, uma matriz que forma o profissional de área específica de conhecimento e outra matriz voltada para a formação do professor dessa área, foi o objeto de estudo de Ayres (2005). O estudo concluiu que

a tentativa de formar professores em uma perspectiva de profissionalização docente, independente do bacharelado, não exclui automaticamente esta tensão, que é constitutiva e estruturante dos cursos que tradicionalmente apresentam estas habilitações (AYRES, 2005 apud TOLENTINO, 2010, p. 15).

As tensões resultantes das diferenças de formação entre bacharéis e licenciados em áreas específicas de conhecimento presentes nas diferenças dos currículos, na aproximação à pesquisa e no status profissional manifestam-se nos cursos noturnos, como mostra Ribeiro (2008), que investigou embates subjacentes à implementação de um curso de Licenciatura noturno em Química ao lado do Curso de Bacharelado já existente. Esses embates se manifestaram pelas disputas de campo, da construção do habitus de seus agentes e dos dividendos simbólicos negociados para conquista de interesses estratégicos específicos.

Os problemas, impasses, dilemas e pontos de tensão presentes na formação em nível de licenciatura, por vezes apresentam tentativas de superação pontuais que ficam nas lembranças dos egressos, como relata Figueiredo Primo (2009) em sua tese de doutorado. Essa investigação detectou um descontentamento generalizado com a estrutura formal do curso representado pela infraestrutura física das unidades de ensino e pelos conteúdos formais trabalhados no interior das disciplinas, que foram avaliados como parcialmente sintonizados às demandas do exercício profissional. No entanto, parte pequena de docentes foi responsável pelas principais marcas do processo de formação acadêmica dos alunos, o que gerou um processo de aprendizado particular. Esse mecanismo de intervenção intencionada desse grupo de docentes configurou o que o autor chamou de currículo marginal na formação para superar as limitações de uma formação que tinha no projeto político-pedagógico uma matriz teórico-filosófica progressista, mas na estrutura curricular das disciplinas, na infraestrutura física e no quadro docente em geral um modelo de formação de três décadas atrás.

Quanto ao entendimento sobre o estágio e o seu papel na formação dos professores, permanece a dificuldade em conceituá-lo. O não entendimento da prática como componente curricular compromete o próprio currículo. 
Em relação aos cursos é recorrentemente questionada a falta de adequação entre a formação acadêmica e o que o professor enfrenta no seu dia a dia; diversos autores sugerem, como modo possível de superar a falta de integração entre a teoria e a prática na formação inicial, considerar o que o professor faz na escola, focalizar as possíveis necessidades e dificuldades que enfrentará no futuro.

\section{Pouca atratividade da carreira ou carência de professores?}

Temos notícias de cursos de Pedagogia que não preencheram as vagas ofertadas para o concurso vestibular. Em algumas universidades, testemunha-se diminuição de candidatos a cursar as modalidades de cursos de licenciatura em algumas áreas específicas. Os meios de comunicação noticiam falta de professores para o ensino básico. Em conversas informais com nossos alunos, muitos afirmam estar cursando licenciatura para ter uma formação a mais além do bacharelado; formação que pode ser útil ao procurar emprego em uma emergência, mas que não é a prioridade de escolha.

A oferta de vagas e de cursos de formação de professores para o ensino básico aumentou nos últimos anos nas universidades públicas (ARAUJO; VIANNA, 2011; GATTI, 2010) tanto na modalidade presencial quanto na Educação a Distância. No entanto, o número de matrículas não é proporcional a esse aumento. Mais ainda, se bem que a quantidade total de formandos tenha aumentado em relação ao número de cursos, estes continuam apresentando evasão significativa de alunos.

Castro (2010), em tese que analisou as condições e representações subjacentes à opção pela carreira docente entre os estudantes e egressos, concluiu que tanto a escolha do curso, quanto a opção pela carreira docente apresentam-se como vias alternativas de acesso ao ensino superior e ao mercado de trabalho frente às limitações impostas pela concorrência nos vestibulares para cursos de maior prestígio, bem como pelo próprio mercado de trabalho. Souto e Paiva (2013), por sua vez, verificaram que para os egressos de cursos de licenciatura a carreira docente não atrai. Muitos licenciados abandonam ou vão abandonar o magistério. Um contingente expressivo de licenciados entrevistados (37\%) não exerce e muitos (aproximadamente 50\%) pretendem deixar o primeiro emprego como professor ou transformá-lo em opção secundária. A preferência para um bom contingente é de continuar os estudos em cursos de pós-graduação.

Não é apenas o número de egressos que leva à falta de professores. Para Araujo e Vianna (2011) o país está formando mais professores. Nas licenciaturas 
que verificaram (biologia, física, matemática e química) o número de concluintes também cresceu. Eles atribuem esse aumento de egressos à reestruturação dos currículos e a redução da evasão de muitos alunos de baixa renda aos programas institucionais de bolsas de permanência. No entanto, estudantes de licenciatura dizem não querer exercer a docência na educação básica, preferem procurar outras opções de carreiras que não o magistério e afirmam que as condições nas escolas os afastam da profissão. Os autores concluem: pode-se falar atualmente em evasão da escola e não evasão da universidade.

\section{Considerações finais}

Ao consultar o Banco de Teses da Capes e os artigos publicados no site SciELO/Brasil nos deparamos com mais de 2.200 teses e mais de 350 artigos originados pela seleção do descritor "formação de professores". A maioria deles descreve questões pontuais, tais como as relacionadas às disciplinas, aos alunos, aos professores e a relatos de experiências, por exemplo. Dos 2.550 documentos selecionados pelos descritores, menos de um quinto trata da formação inicial de professores nas universidades públicas e poucos tratam de questões de fundo que envolvem a formação inicial, a concretização de políticas públicas expressas em projetos efetivos, a indefinição da profissão, a complexidade da formação, a relação entre teoria e prática, entre outros.

Alguns dos autores identificados por meio do site SciELO com aquele descritor, entre eles, Gatti (2010), Lüdke e Boing (2012) e Saviani (2009), vêm denunciando os descaminhos da formação de professores no Brasil há anos. Os problemas, impasses, dilemas e pontos de tensão são praticamente os mesmos há mais de 70 anos e alguns datam do fim do século XIX, quando iniciou a formação institucionalizada de professores no Brasil (SAVIANI, 2009).

Neste artigo, identificamos diferentes questões abordadas sobre a formação de professores nas universidades públicas brasileiras evidenciando a diversidade de problemas, impasses, dilemas e pontos de tensão que são conflitantes nos debates sobre formação de professores. O panorama que se apresentou evidencia a recorrência de temas que permanecem gerando conflitos, a necessidade de buscar soluções e a complexidade do campo educativo. Os que se destacaram dizem respeito à profissão docente, aos cursos de formação de professores, à pouca atratividade docente e à falta de professores.

Há que se considerar o desenvolvimento tecnológico da comunicação e da informação nos últimos tempos, desenvolvimento esse que modificou o pano- 
rama da Educação Brasileira no que concerne ao aumento de número de vagas nas universidades, particularmente quanto às Licenciaturas. Também há que se considerar os programas institucionais que colaboram para esse aumento. Se, por um lado, contribuem para modificar os resultados da crítica equação entre demanda de professores para a Educação Básica e o número deles formados, por outro, novos aspectos emergem e engrossam os problemas, impasses, dilemas e pontos de tensão recorrentes há décadas, acentuadamente desde a década de 1950.

A questão da qualidade da formação permanece incógnita. A pouca atratividade para a carreira docente é um fator considerável para minimizar a desproporcionalidade entre expectativa quantitativa de formação e professores efetivamente em sala de aula. Há que se perguntar onde está uma significativa parcela dos professores para a Educação Básica formados nos cursos de Licenciatura no território brasileiro, tanto na modalidade presencial quanto na modalidade a distância.

Algumas questões relacionadas, por exemplo, à melhoria da qualidade das condições de formação e de valorização do trabalho dos professores que dependem, por exemplo, de políticas e planos governamentais em longo prazo, de tão repetidas, insistidas e reivindicadas, se tornaram utopias, como nos disse Freitas (2007). Pensamos que, como todas as utopias, cumprem sua função: dão-nos esperança.

Finalizamos com uma citação de Escher sobre sua obra "Relatividade", de 1953.

Três planos de gravitação agem aqui verticalmente uns sobre os outros. Três superfícies terrestres, vivendo em cada uma delas seres humanos, intersectam-se em ângulo recto. Dois habitantes de mundos diferentes não podem andar, sentar-se ou ficar em pé no mesmo solo, pois a sua concepção de horizontal e vertical não se conjuga. Eles podem, contudo, usar a mesma escada. Na escada mais alta das aqui representadas, movemse, lado a lado, duas pessoas na mesma direcção. Todavia, uma desce e a outra sobe. É claramente impossível um contacto entre ambas, pois vivem em mundos diferentes e não sabem, portanto, da existência uma da outra. (ESCHER, 1994, p. 15).

Analogias entre problemas, impasses, dilemas e pontos de tensão atuais na formação de professores para a Educação Básica em instituições públicas brasileiras abordadas neste artigo e a obra de Escher mencionada ficam para a criatividade do leitor. 


\section{REFERÊNCIAS}

ARAUJO, R. S.; VIANNA, D. M. A carência de professores de ciências e matemática na educação básica e a ampliação das vagas no ensino superior. Ciência \& Educação, Bauru, v. 17, n. 4, p. 807-822, 2011.

AYRES, A. C. B. M. Tensão entre matrizes: um estudo a partir do curso de Ciências Biológicas da Faculdade de Formação de Professores/UERJ. Tese (Doutorado em Educação) - Centro de Estudos Sociais Aplicados, Faculdade de Educação, Universidade Federal Fluminense, Niterói, set. 2005.

CANAN, S. R. Diretrizes nacionais para a formação de professores da educação básica: tensões e limites entre o específico e o pedagógico na formação docente. Tese (Doutorado em Educação) - Universidade do Rio dos Sinos, São Leopoldo, 2009.

CASTRO, S. M. V. de. Biólogos, da universidade ao mercado de trabalho: um estudo entre estudantes e egressos do Curso de Licenciatura em Biologia. Tese (Doutorado em Educação) - Departamento de Educação, Pontifícia Universidade Católica do Rio de Janeiro, Rio de Janeiro, dez. 2010.

ERNST, Bruno. O espelho mágico de M. C. Escher. Berlin: Taschen, 1991.

ESCHER, M. C. Gravuras e desenhos. Hamburgo: Taschen, 1994.

FIGUEIREDO PRIMO, C. P. O curso de licenciatura em educação física da UFBA: uma análise da formação acadêmica e do exercício profissional de seu egresso no mundo do trabalho. Tese (Doutorado em Educação) - Universidade Federal da Bahia, Salvador, 2009.

FREITAS, H. C. L. A (nova) política de formação de professores: a prioridade postergada. Educação \& Sociedade, São Paulo, v. 28, n. 100 - Especial, p. 645-650, out. 2007.

FRISON, M. D. A produção de saberes docentes articulada à formação inicial de professores de química: implicações teórico-práticas na escola de nível médio. Tese (Doutorado em Educação em Ciência Química da Saúde) - Instituto de Ciências Básicas da Saúde, Universidade Federal do Rio Grande do Sul, Porto Alegre, 2012.

GATTI, B. A. A formação docente: o confronto necessário Professor x Academia. Cadernos de Pesquisa, Fundação Carlos Chagas, São Paulo, n. 81, p. 85-90, 1992.

. Formação de professores no Brasil: características e problemas. Educação \& Sociedade, Campinas, v. 31, n. 113, p. 1.355-1.379, out./dez. 2010.

GUÉRIOS, E. Espaços oficiais e intersticiais da formação docente: histórias de um grupo de professores na área de Ciências e Matemática. Tese (Doutorado em Educação) - Faculdade de Educação, Universidade Estadual de Campinas, Campinas, 2002.

LÜDKE, M.; BOING, L. A. Do trabalho à formação de professores. Cadernos de Pesquisa, São Paulo, v. 42, n. 146, p. 425-451, maio/ago. 2012. 
MARQUES, C. V. V. C. O. Perfil dos cursos de formação de professores dos programas de licenciatura em química das instituições públicas de ensino superior da região nordeste do país. Tese (Doutorado em Química) - Centro de Ciências Exatas e de Tecnologia, Universidade Federal de São Carlos, São Carlos, 2010.

MINDAL, C. M. A graduação nos trabalhos da ANPEd (1996-2003). Tese (Doutorado em Psicologia da Educação) - Programa de Estudos Pós-Graduados em Educação: Psicologia da Educação, Pontifícia Universidade Católica de São Paulo, São Paulo, 2006.

OLIVEIRA, L. M. de. Políticas educacionais na formação da professora dos anos iniciais do Ensino Fundamental em cursos de licenciatura. Ensaio: Avaliação e Políticas Públicas em Educação, Rio de Janeiro, v. 18, n. 67, p. 235-252, abr./jun. 2010.

PEREIRA, J. E. D. Relações de poder no interior do campo universitário e as licenciaturas. Cadernos de Pesquisa, Fundação Carlos Chagas, São Paulo, n. 111, p. 182-201, dez. 2000.

PROENÇA, M. G. S. Disciplinas pedagógicas nas licenciaturas: representações dos docentes sobre seu processo identitário e relevância do seu trabalho. Tese (Doutorado em Educação) - Centro de Ciências Humanas e Sociais, Universidade Federal de Mato Grosso do Sul, Campo Grande, 2010.

RIBEIRO, L. C. dos S. A criação da licenciatura noturna em química da UFRJ: embates, retóricas e conciliações. Tese (Doutorado em Educação: História, Política e Sociedade) - Pontifícia Universidade Católica de São Paulo, São Paulo, set. 2008.

ROSSO, A. J. et al. Novas diretrizes curriculares nacionais para a formação de professores e algumas novas ficções na leitura da escola. Ensaio: Avaliação e Políticas Públicas em Educação, Rio de Janeiro, v. 18, n. 69, p. 821-842, out./dez. 2010.

SAVIANI, D. Formação de professores: aspectos históricos e teóricos do problema no contexto brasileiro. Revista Brasileira de Educação, ANPEd, Rio de Janeiro, v. 14, n. 40, p. 143-155, jan./abr. 2009.

SILVA, R. N.; ESPOSITO, Y. L.; SAMPIO, M. M.; QUINTEIRO, J. Formação de professores no Brasil. São Paulo: FCC/REDUC, 1991.

SOUTO, R. M. A.; PAIVA, P. H. A. A. de. A pouca atratividade da carreira docente: um estudo sobre o exercício da profissão entre egressos de uma licenciatura em matemática. Pro-Posições, Campinas, v. 24, n. 1, p. 201-224, jan./abr. 2013.

TOLENTINO, P. C. As referências da formação inicial na representação dos licenciandos em ciências biológicas da Universidade Estadual de Ponta Grossa. Dissertação (Mestrado em Educação: Ensino-Aprendizagem) - Setor de Ciências Humanas, Letras e Artes, Universidade Estadual de Ponta Grossa, Ponta Grossa, 2010.

Texto recebido em 15 de julho de 2013.

Texto aprovado em 08 de agosto de 2013. 